\title{
USAHA PENINGKATAN PRODUKTIVITAS PADA PRODUKSI CPO DENGAN MENGGUNAKAN METODE OBJECTIVE MATRIKS (OMAX) DI PT. INKA BINA AGRO WISESA
}

\author{
Defi Irwansyah* dan M Hidayat \\ Jurusan Teknik Industri, Fakultas Teknik, Universitas Malikussaleh, Aceh, Indonesia \\ *Corresponding Author: defiirwansyah@unimal.ac.id
}

\begin{abstract}
Abstrak - PT. Inka Bina Agro Wisesa adalah salah satu perusahaan di Desa Guha Uleue, Kecamatan Kuta makmur, Kabupaten Aceh Utara, provinsi Aceh yang menghasilkan produk berupa minyak mentah atau CPO (Crude Palm Oil) dan Kernel. PT. Inka Bina Agro Wisesa yang dituntut untuk melakukan peningkatan produktivitas. Pengukuran produktivitas sangatlah penting karena pada pengukuran produktivitas dapat menentukan apakah perusahaan tersebut memenuhi target produktivitas untuk produksi atau tidak. Oleh karena itu, diperlukan pengukuran produktivitas untuk mengetahui nilai produktivitas dan usaha peningkatan produktivitas pada produksi CPO di PT. Inka Bina Agro Wisesa. Salah satu metode pengukuran produktivitas yang dapat digunakan untuk menyelesaikan masalah tersebut adalah Objective Matrix (OMAX). Metode ini digunakan untuk mengidentifikasikan faktor-faktor yang berpengaruh dan yang kurang berpengaruh terhadap peningkatan produktivitas. Hasil perhitungan indeks produktivitas setiap periode menggambarkan penurunan dan peningkatan produktivitas yang dicapai oleh perusahaan. Pada hasil perhitungan PT. Inka Bina Agro Wisesa setiap bulan mengalami perubahan produktivitas yang tidak stabil, pada bulan November 2019 Produktivitas PT. Inka Bina Agro Wisesa mengalami penurunan pada bulan November 2019 sebesar - 80,39\% dan mengalamai peningkatan yang cukup tinggi pada bulan berikutnya yaitu bulan Desember sebesar 594,96\%. Pada bulan berikutnya PT. Inka Bina Agro Wisesa. Pada bulan berikutnya PT. Inka Bina Agro Wisesa mengalami penurunan produktivitasnya pada bulan Januari 2020 dan pada bulan Februari 2020 sampai -23,73\%. Selanjutnya produktivitas pada bulan Maret hingga bulan September 2020 produktivitas PT. Inka Bina Agro Wisesa tidak stabil terjadi naik dan penurunan.
\end{abstract}

Kata Kunci: Produktivitas, Objective Matrix (OMAX), Indikator Pencapaian, Indeks Pencapaian.

\section{Pendahuluan}

Kelapa sawit (Elaeis) adalah tumbuhan industri penting penghasil minyak masak, minyak industri, maupun bahan bakar (biodiesel). Perkebunannya menghasilkan keuntungan besar sehingga banyak hutan dan perkebunan lama dikonversi menjadi perkebunan kelapa sawit. Indonesia adalah penghasil minyak kelapa sawit terbesar di dunia.

PT. Inka Bina Agro Wisesa adalah salah satu perusahaan di Desa Guha Uleue, Kecamatan Kuta makmur, Kabupaten Aceh Utara, provinsi Aceh yang menghasilkan produk berupa minyak mentah atau CPO (Crude Palm Oil). Mengamati perkembangan produksi CPO (Crude Palm Oil) di PT. Inka Bina Agro Wisesa, hingga saat ini PT. Inka Bina Agro Wisesa menetapkan target produksi minimum TBS yang harus diolah mencapai 30 ton dalam sekali perebusan dengan target minimum produksi yaitu 600 ton/hari.. Dalam satu hari, PT. Inka Bina Agro Wisesa (IBAS) menjalankan kegiatan produksinya selama 24 jam setiap hari (non-stop) dimana jam kerja ini dibagi dalam tiga shift kerja.

PT. Inka Bina Agro Wisesa yang dituntut untuk melakukan peningkatan produktivitas. Dimana perusahaan tidak pernah melakukan pengukuran produktivitas proses produksi mereka. Maka, Pencapaian target produksi minimum pada PT. Inka Bina Agro Wisesa belum tentu menjamin apakah perusahan ini memiliki tingkat produktivitas yang baik atau buruk. Pengukuran produktivitas sangatlah penting karena pada pengukuran produktivitas dapat menentukan apakah perusahaan tersebut memenuhi target 
produktivitas untuk produksi atau tidak. Oleh karena itu, diperlukan pengukuran produktivitas untuk mengetahui nilai produktivitas dan usaha peningkatan produktivitas pada produksi CPO di PT. Inka Bina Agro Wisesa.

Berdasarkan latar belakang di atas penulis tertarik untuk melakukan penelitian dengan judul "Usaha Peningkatan Produktivitas Pada Produksi Cpo Dengan Menggunakan Metode Objective Matriks (Omax) Di Pt. Inka Bina Agro Wisesa".

Adapun tujuan yang ingin dicapai dalam melakukan penelitian ini adalah sebagai berikut:

a. Untuk dapat mengetahui produktivitas pada produksi CPO dengan menggunakan metode Objective Matrix (OMAX) di PT. Inka Bina Agro Wisesa.

b. Untuk dapat mengetahui usaha peningkatan produktivitas pada produksi CPO di PT. Inka Bina Agro Wisesa.

\section{Tinjauan Pustaka}

Pengertian Produktivitas, David J. Summanth mendefinisikan produktivitas sebagai rasio antara jumlah output yang dihasilkan dengan jumlah input yang digunakan. Secara umum produktivitas dapat diartikan sebagai ukuran tentang seberapa baik sumber daya digunakan secara bersama-sama dalam sebuah organisasi untuk mendapatkan seperangkat hasil yang diharapkan.

\section{Metode Pengukuran Objective Matrix (OMAX)}

Objective Matrix adalah suatu sistem pengukuran produktivitas parsial yang dikembangkan untuk memantau produktivitas di suatu perusahaan atau di tiap bagian saja dengan kriteria produktivitas yang sesuai dengan keberadaan bagian tersebut.

Adapun langkah-langkah penelitian Taguchi adalah sebagai berikut:

\section{Menetapkan Kriteria Produktivitas}

Penetapan kriteria pengukuran agar lebih memfokuskan pada kategori utama penetapan kriteria produktivitas, yaitu:

Kriteria efisiensi, yaitu menunjukkan bagaimana penggunaan sumber daya perusahaan digunakan sehemat mungkin. Kriteria ini meliputi :

Rasio I : perbandingan antara jumlah output produk yang dihasilkan dengan bahan baku terpakai.

Rasio II : perbandingan antara jumlah output produk yang dihasilkan dengan jumlah jam kerja terpakai.

Kriteria inferensial, yaitu kriteria yang secara tidak langsung dapat mempengaruhiproduktivitas, kriteria ini meliputi :

Rasio III : merupakan perbandingan antara jumlah absensi tenaga kerja dengan jam kerja.

Rasio IV : merupakan perbandingan antara jumlah jam kerja mesin dengan jam kerusakan mesin.

\section{Menghitung nilai rasio.}

Untuk menghitung nilai rasio dapat menggunakan rumus:

Rasio (1) = _umlah output produk

pemakaian bahan baku utama

Rasio $(2)=$ jumlah output produk jam kerja

Rasio $(3)=$ absensi(jam) jam kerja yang tersedia = absensi karayawan(orang) $\mathrm{x}$ jam kerja jam kerja yang tersedia

Rasio $(4)=\ldots$ jam kerja mesin Jam kerusakan mesin

Keterangan:

Rasio (1) = produktivitas bahan baku

Rasio (2) = prouktifitas waktu produksi

Rasio $(3)$ = produktivitas tenaga kerja

Rasio (4) = produtifitas mesin

\section{Menetapkan Sasaran Akhir Dan Skor}

Kenaikan level 1 dan 2 dilakukan dengan cara interpolasi, yaitu:

$$
\frac{\text { Level 3-Level } 0}{3-0}
$$

Kenaikan level 4 sampai dengan 9 dilakukan dengan cara interpolasi, yaitu:

$$
\frac{\text { Level } 10-\text { Level } 3}{10-3}
$$

\section{Penetapan Bobot Kriteria Kinerja}

Jumlah bobot dari seluruh kriteria kinerja yang diukur adalah 100, dimana kriteria yang memiliki tingkat kepentingan lebih tinggi mendapat bobot yang tinggi pula.

\section{Mencari Nilai Performansi}

Nilai dari pencapaian yang berhasil diperoleh untuk setiap kriteria pada periode tertentu didapat dengan mengalikan skor pada kriteria tertentu dengan bobot kriteria tersebut. Adapun rumus yang digunakan untuk menghitung nilai produktivitas, yaitu:

Nilai produktivitas $=$ skor aktual $\mathrm{x}$ bobot

\section{Menghitung Indikator Pencapaian}

Peningkatan produktivitas ditentukan dari besarnya kenaikan indikator pencapaian yang terjadi. Adapun rumus yang digunakan untuk menghitung nilai indikator pencapaian yaitu:

Indikator pencapaian $=$ NP rasio $1+\ldots .+$ NP ke-n

Keterangan: NP $=$ Nilai Produktivitas

\section{Menghitung Indeks Produktivitas}

Pengukuran tingkat produktivitas perusahaan dilakukan terhadap hasil perhitungan diatas. Pola pertumbuhan 
produktivitas dianalisa untuk mengetahui perkembangan perusahaanselama periode pengukuran. Perhitungan persentase perubahan indeks produktivitas setiap periode pengukuran dapat dihitung dengan rumus berikut:

$$
\text { Indeks Produktivitas }=\frac{I P_{i}-I P_{i-1}}{I P_{i}-1} \times 100 \%
$$

Keteragan:

$\mathrm{IP}_{\mathrm{i}}=$ Nilai indikator pencapaian di satu periode

$\mathrm{IP}_{\mathrm{i}-1}=$ Nilai indikator pencapaian awal

\section{Metodelogi Penelitian}

Untuk mendapatkan berbagai macam data yang dibutuhkan dalam penelitian ini, peneliti menggunakan teknik pengumpulan data, yaitu:

a. Observasi

Observasi yaitu melakukan pengamatan secara langsung kebagian produksi yang berkaitan dengan proses pengolahan minyak di PT. Inka Bina Agro Wisesa.

b. Wawancara

Wawancara dilakukan untuk mendapatkan data perusahaan, penulis melakukan wawancara langsung yang melibatkan pegawai pada instansi yang bersangkutan yaitu Bapak Gianto selaku Asisten Produksi Di PT. Inka Bina Agro Wisesa . Wawancara yang penulis lakukan yaitu wawancara secara lisan berhubungan dengan objek studi.

c. Metode Dokumentasi

Pengumpulan data dengan cara mengambil data yang telah ada, seperti mengambil data dari administrasi pabrik PT. Inka Bina Agro Wisesa, dan sebagainya.

\section{Hasil Dan Pembahasan}

Objactive matrix (OMAX) adalah salah satu sistem pengukuran produktivitas yang dikembangkan untuk memantau produktivitas di tiap bagian perusahaan dengan kriteria produktivitas yang sesuai dengan keberadaan bagian tersebut (objective).

1. Nilai rasio dari setiap kriteria dapat dilihat pada tabel 1 berikut:

Tabel 1. Nilai Rasio

\begin{tabular}{|c|c|c|c|c|}
\hline Bulan & Rasio 1 & Rasio 2 & Rasio 3 & Rasio 4 \\
\hline Okt & 0.16 & 4.52 & 0.12 & 208.00 \\
\hline Nov & 0.15 & 3.60 & 0.12 & 312.00 \\
\hline Des & 0.17 & 4.09 & 0.15 & 0.00 \\
\hline Jan & 0.16 & 4.52 & 0.04 & 0.00 \\
\hline Feb & 0.16 & 4.57 & 0.12 & 0.00 \\
\hline Mar & 0.16 & 4.66 & 0.08 & 0.00 \\
\hline Apr & 0.16 & 4.84 & 0.15 & 0.00 \\
\hline
\end{tabular}

Sumber: Pengolahan data
Tabel 1. (Lanjutan)

\begin{tabular}{|c|c|c|c|c|}
\hline Mei & 0.16 & 4.75 & 0.08 & 624.00 \\
\hline Jun & 0.17 & 4.48 & 0.04 & 312.00 \\
\hline Jul & 0.17 & 4.20 & 0.04 & 624.00 \\
\hline Agts & 0.17 & 4.36 & 0.08 & 0.00 \\
\hline Sep & 0.17 & 4.39 & 0.04 & 624.00 \\
\hline Rata-rata & 0.16 & 4.42 & 0.09 & 225.33 \\
\hline
\end{tabular}

Sumber: Pengolahan data

\section{Nilai skala interval dan skala tingkat produktivitas} Berikut merupakan hasil perhitungan nilai skala interval dan skala tingkat produktivitas.

Skala interval $=\underline{\text { sasaran jangka panjang }- \text { pencapai awal }}$ $10-3$

Skor $4=$ skor $3+$ skala interval $=0,16+0,008=0,168$ Pengisian skala tingkat pada skor 5 sampai 10 , caranya sama dengan perhitungan skala tingkat untuk skor 4 . Skor 2 = skor 3 - skala interval $=0,16-0,008=0,152$ Pengisian skala tingkat untuk skor 1 sampai 0 , caranya sama dengan perhitungan skala tingkat untuk skor 2 .

Tabel 2. Skala Tingkat Produktivitas Bahan Baku

\begin{tabular}{|c|c|}
\hline Skor & Skala tingkat produktivitas \\
\hline 10 & 0,216 \\
\hline 9 & 0,208 \\
\hline 8 & 0,2 \\
\hline 7 & 0,192 \\
\hline 6 & 0,184 \\
\hline 5 & 0,176 \\
\hline 4 & 0,168 \\
\hline 3 & 0,16 \\
\hline 2 & 0,152 \\
\hline 1 & 0,144 \\
\hline 0 & 0,136 \\
\hline
\end{tabular}

Sumber: Hasil Pengolahan Data

Tabel 3. Skala Tingkat Produktivitas Waktu Produksi

\begin{tabular}{|c|c|}
\hline Skor & Skala tingkat produktivitas \\
\hline 10 & 5,33 \\
\hline 9 & 5,2 \\
\hline 8 & 5,07 \\
\hline 7 & 4,94 \\
\hline 6 & 4,81 \\
\hline 5 & 4,68 \\
\hline 4 & 4,55 \\
\hline 3 & 4,42 \\
\hline 2 & 4,29 \\
\hline 1 & 4,16 \\
\hline 0 & 4,03 \\
\hline
\end{tabular}

Sumber: Hasil Pengolahan Data 
Tabel 4. Skala Tingkat Produktivitas Jam Kerja

\begin{tabular}{|c|c|}
\hline Skor & Skala tingkat Produktivitas \\
\hline 10 & 0,041 \\
\hline 9 & 0,048 \\
\hline 8 & 0,055 \\
\hline 7 & 0,062 \\
\hline 6 & 0,069 \\
\hline 5 & 0,076 \\
\hline 4 & 0,083 \\
\hline 3 & 0,09 \\
\hline 2 & 0,097 \\
\hline 1 & 0,104 \\
\hline 0 & 0,111 \\
\hline
\end{tabular}

Sumber: Hasil Pengolahan Data

Tabel 5. Skala Tingkat Produktivitas Mesin

\begin{tabular}{|c|c|}
\hline Skor & Skala tingkat Produktivitas \\
\hline 10 & 90,16 \\
\hline 9 & 109,47 \\
\hline 8 & 128,78 \\
\hline 7 & 148,09 \\
\hline 6 & 167,4 \\
\hline 5 & 186,71 \\
\hline 4 & 206,02 \\
\hline 3 & 225,33 \\
\hline 2 & 244,64 \\
\hline 1 & 263,95 \\
\hline 0 & 283,26 \\
\hline
\end{tabular}

Sumber: Hasil Pengolahan Data

\section{Penetapan Bobot Kriteria Kinerja}

Bobot kriteria kinerja yang digunakan dalam pengukuran produktivitas pada proses produksi $C P O$ di PT. Inka Bina Agro Wisesa ini diperoleh melalui wawancara karyawan yang berada pada level atas dalam struktural jabatan pada bagian proses produksi dan menejer pabrik.

Tabel 6. Data Bobot Kriteria Kinerja

\begin{tabular}{|c|c|c|c|c|}
\hline Responden & Rasio 1 & Rasio 2 & Rasio 3 & Rasio 4 \\
\hline 1 & 5 & 5 & 5 & 4 \\
\hline 2 & 5 & 4 & 4 & 4 \\
\hline 3 & 5 & 4 & 4 & 5 \\
\hline 4 & 5 & 5 & 3 & 4 \\
\hline Total & 20 & 18 & 16 & 18 \\
\hline
\end{tabular}

Sumber: Hasil Wawancara

Nilai bobot diatas dikonversikan ke dalam skala 100\% agar kemudian dapat dimasukkan dalam matrik sasaran. Perhitungan nilai bobot untuk rasio 1 adalah sebagai berikut:

Nilai Bobot Rasio I $=\frac{20}{72} \times 100 \%=27,78 \%$
Tabel 7. Penetapan Bobot Kriteria Kinerja

\begin{tabular}{|c|c|c|c|}
\hline Rasio & Bobot & $\begin{array}{c}\text { Total } \\
\text { Bobot }\end{array}$ & Persentase (\%) \\
\hline Rasio 1 & 20 & 72 & 27,78 \\
\hline Rasio 2 & 18 & 72 & 25 \\
\hline Rasio 3 & 16 & 72 & 22,22 \\
\hline Rasio 4 & 18 & 72 & 25 \\
\hline
\end{tabular}

Sumber: Hasil Pengolahan Data

Tabel 8. Persentase Kriteria Buruk

\begin{tabular}{|l|c|c|}
\hline & $\begin{array}{c}\text { Jumlah Kriteria } \\
\text { Buruk }\end{array}$ & $\begin{array}{c}\text { Persentase Kriteria } \\
\text { Buruk (\%) }\end{array}$ \\
\hline Rasio 1 & 1 & 7,69 \\
\hline Rasio 2 & 3 & 23,08 \\
\hline Rasio 3 & 4 & 30,77 \\
\hline Rasio 4 & 5 & 38,46 \\
\hline Total & 13 & \multicolumn{1}{|c}{} \\
\cline { 1 - 2 } & &
\end{tabular}

Sumber: Hasil Pengolahan Data

\section{Pembentukan Matrik OMAX}

Nilai-nilai yang ada dalam pembentukan matrik omax adalah nilai tahap awal, nilai sasaran akhir, nilai terendah, dan nilai bobot masing-masing rasio. Berikut adalah tabel pembentukan matrik OMAX dari bulan Oktober 2019 September 2020.

Tabel 9. Matrik Sasaran (Objective matrik) perusahaan PT. Inka Bina Agro Wisesa Oktober 2019

\begin{tabular}{|c|c|c|c|c|c|c|}
\hline Kriteria & \multicolumn{2}{|c|}{ Efesiensi } & \multicolumn{2}{|c|}{ Inferensia } & \multirow{3}{*}{ Skor } & \multirow{3}{*}{ Keterangan } \\
\hline Rasio-rasio & Rasio 1 & Rasio 2 & Rasio 3 & Rasio 4 & & \\
\hline Nilai Aktual & 0.16 & 4.52 & 0.12 & 208.00 & & \\
\hline & 0,216 & 5,33 & 0,041 & 90,16 & 10 & Sangat Baik \\
\hline & 0,208 & 5,2 & 0,048 & 109,47 & 9 & \multirow{4}{*}{ Baik • } \\
\hline & 0,2 & 5,07 & 0,055 & 128,78 & 8 & \\
\hline & 0,192 & 4,94 & 0,062 & 148,09 & 7 & \\
\hline & 0,184 & 4,81 & 0,069 & 167,4 & 6 & \\
\hline & 0,176 & 4,68 & 0,076 & 186,71 & 5 & \multirow{3}{*}{ Sedang } \\
\hline & 0,168 & 4,55 & 0,083 & 206,02 & 4 & \\
\hline & 0,16 & 4,42 & 0,09 & 225,33 & 3 & \\
\hline & 0,152 & 4,29 & 0,097 & 244,64 & 2 & \multirow{2}{*}{ Buruk } \\
\hline & 0,144 & 4,16 & 0,104 & 263,95 & 1 & \\
\hline & 0,136 & 4,03 & 0,111 & 283,26 & 0 & Sangat Buruk \\
\hline Skor Aktual & 3 & 4 & 0 & 4 & & \\
\hline Bobot & 27,78 & 25 & 22,22 & 25 & & \\
\hline $\begin{array}{c}\text { Nilai } \\
\text { Pefformance }\end{array}$ & 83,34 & 100 & 0,00 & 100 & & \\
\hline Keterangan & Sedang & Sedang & $\begin{array}{l}\text { Sangat } \\
\text { Buruk }\end{array}$ & Sedang & & \\
\hline
\end{tabular}

Berdasarkan Matriks Sasaran yang diperoleh dari bulan Oktober 2019 sampai bulan September 2020, maka nilai skor kriteria kinerja PT. Inka Bina Agro Wisesa dari bulan Oktober 2019 sampai bulan September 2020, dapat dilihat pada tabel 10.:

Tabel 10. Rekapitulasi Nilai Skor

\begin{tabular}{|c|c|c|c|c|}
\hline Bulan & Rasio 1 & Rasio 2 & Rasio 3 & Rasio 4 \\
\hline Okt & 3 & 4 & 0 & 4 \\
\hline Nov & 2 & 0 & 0 & 0 \\
\hline Des & 4 & 1 & 0 & 10 \\
\hline Jan & 3 & 4 & 10 & 10 \\
\hline
\end{tabular}

Tabel 10. (Lanjutan) 


\begin{tabular}{|c|c|c|c|c|}
\hline Feb & 3 & 4 & 3 & 10 \\
\hline Mar & 3 & 5 & 4 & 10 \\
\hline Apr & 3 & 6 & 0 & 10 \\
\hline Mei & 3 & 5 & 4 & 0 \\
\hline Jun & 5 & 3 & 10 & 0 \\
\hline Jul & 4 & 2 & 10 & 0 \\
\hline Agts & 4 & 3 & 4 & 10 \\
\hline Sep & 4 & 3 & 10 & 0 \\
\hline
\end{tabular}

Sumber: Hasil Pengolahan Data

\section{Perhitungan Indikator Pencapaian}

Perhitungan indikator pencapaian dilakukan untuk mengetahui pencapaian setiap bulannya selama periode pengukuran, yaitu mulai dari bulan Oktober 2019 sampai dengan bulan September 2020. Berikut merupakan hasil perhitungan indikator pencapaian:

Tabel 11. Hasil Indiktor Pencapaian

\begin{tabular}{|c|c|c|c|c|c|}
\hline Bulan & Rasio 1 & Rasio 2 & Rasio 3 & Rasio 4 & $\begin{array}{c}\text { Indikator } \\
\text { Pencapaian }\end{array}$ \\
\hline Okt & 83,34 & 100 & 0,00 & 100 & 283.34 \\
\hline Nov & 55,56 & 0,00 & 0,00 & 0,00 & 55.56 \\
\hline Des & 111,12 & 25 & 0,00 & 250 & 386.12 \\
\hline Jan & 83,34 & 100 & 222,2 & 250 & 655.54 \\
\hline Feb & 83,34 & 100 & 66,66 & 250 & 500 \\
\hline Mar & 83,34 & 125 & 88,88 & 250 & 547.22 \\
\hline Apr & 83,34 & 150 & 0,00 & 250 & 483.34 \\
\hline Mei & 83,34 & 125 & 88,88 & 0,00 & 297.22 \\
\hline Jun & 138,9 & 75 & 222,2 & 0,00 & 436.1 \\
\hline Jul & 111,12 & 100 & 222,2 & 0,00 & 433.32 \\
\hline Agts & 111,12 & 75 & 88,88 & 250 & 525 \\
\hline Sep & 111,12 & 75 & 222,22 & 0,00 & 408.34 \\
\hline
\end{tabular}

Sumber: Hasil Pengolahan Data

Nilai indikator pencapaian yang paling rendah adalah pada bulan November 2019 yaitu sebesar 55,56. Sedangkan nilai indikator pencapaian yang paling besar adalah pada bulan Januari 2020 yaitu sebesar 655,54. Grafik indikator pencapaian selama periode pengukuran dapat dilihat pada Gambar 1 berikut :

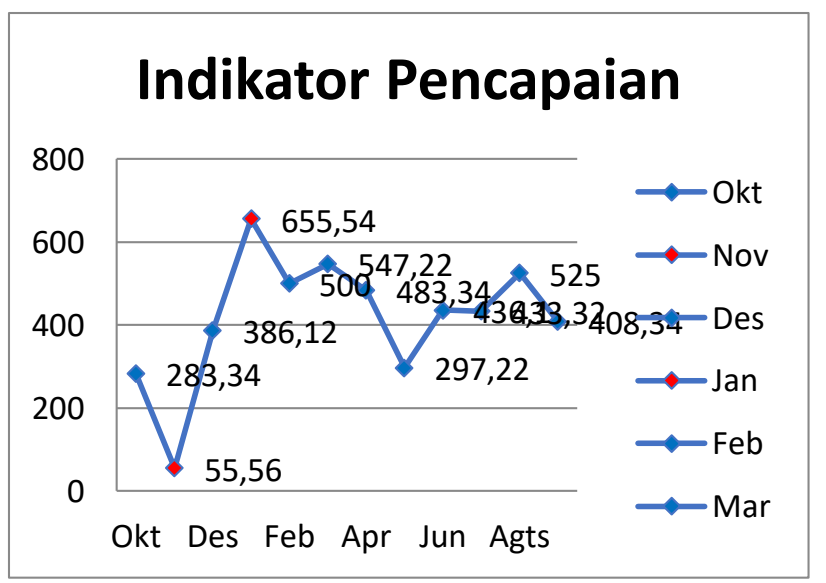

Gambar 1. Grafik Indikator Pencapaian

6. Perhitungan indeks produktivitas

Hasil perhitungan indeks produktivitas setiap periode menggambarkan penurunan dan peningkatan produktivitas yang dicapai oleh perusahaan. Tujuan perhitungan indeks produktivitas perusahaan adalah sebagai alat dalam menganalisa perubahan indeks produktivitas perusahaan. Perhitungan indeks produktivitas pada bulan Oktober 2019 adalah sebagai berikut :

Indeks Produktivitas pada Oktober $2019=$ $\frac{283,34-0}{0} \times 100 \%=0 \%$

Hasil perhitungan indeks produktivitas pada produksi CPO PT. IBAS setiap bulan mulai dari bulan Oktober 2019 sampai dengan bulan September 2020 dapat dilihat pada Tabel 12 dibawah ini:

Tabel 12. Hasil Indeks Produktivitas

\begin{tabular}{|c|c|c|}
\hline Bulan & $\begin{array}{c}\text { Indikator } \\
\text { Pencapaian }\end{array}$ & $\begin{array}{c}\text { Indeks } \\
\text { Produktivitas }\end{array}$ \\
\hline Okt & 283.34 & 0,00 \\
\hline Nov & 55.56 & $-80,39$ \\
\hline Des & 386.12 & 594,96 \\
\hline Jan & 655.54 & 69,78 \\
\hline Feb & 500 & $-23,73$ \\
\hline Mar & 547.22 & 9,44 \\
\hline Apr & 483.34 & $-11,67$ \\
\hline Mei & 297.22 & $-38,51$ \\
\hline Jun & 436.1 & 46,73 \\
\hline Jul & 433.32 & $-0,64$ \\
\hline Agts & 525 & 0,21 \\
\hline Sep & 408.34 & $-22,22$ \\
\hline
\end{tabular}

\section{Sumber: Hasil Pengolahan Data}

Hasil pengukuran indeks produktivitas menunjukkan bahwa indeks yang paling rendah adalah pada bulan November 2019 yaitu sebesar - 80,39\%, dan indeks yang paling tinggi adalah pada bulan Desember 2019, sebesar $594,96 \%$. Grafik perubahan indeks dari bulan ke bulan dapat dilihat dalam Gambar 2 di bawah ini :

\section{Indeks Produktivitas}

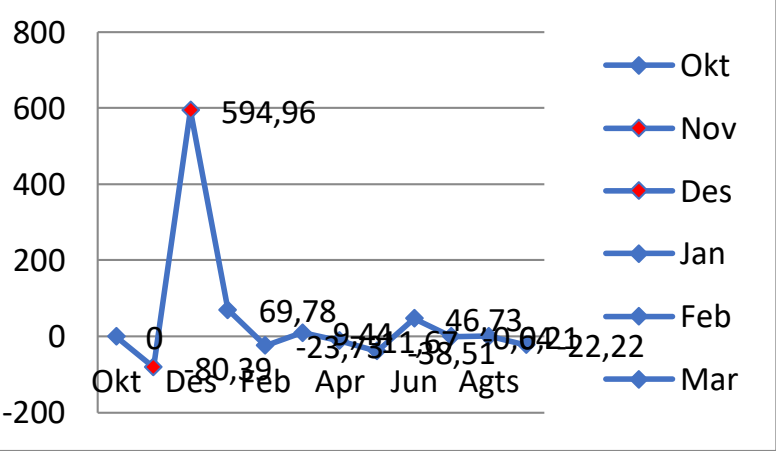

Gambar 2. Grafik Indeks Produktivitas

\section{Analisis dan Evaluasi Hasil Pengukuran Produktivitas}

Setelah diperoleh indeks produktivitas maka dilakukan analisis dan evaluasi terhadap hasil pengukuran produktivitas tersebut seperti berikut.

1. Analisis Indeks Produktivitas

Hasil perhitungan indeks produktivitas setiap periode menggambarkan penurunan dan peningkatan 
produktivitas yang dicapai oleh perusahaan. Pada gambar 3.5 dapat dilihat bahwa setiap bulan mengalami perubahan produktiitas, terutama pada bulan November 2019 hingga bulan Desember 2019. Produktivitas PT. Inka Bina Agro Wisesa mengalami penurunan pada bulan November 2019 sebesar - 80,39\% dan mengalamai peningkatan yang cukup tinggi pada bulan berikutnya yaitu bulan Desember 2019 sebesar 594,96\%. Pada bulan berikutnya PT. Inka Bina Agro Wisesa mengalami penurunan produktivitasnya pada bulan Januari 2020 dan pada bulan Februari 2020 sampai -23,73\%. Selanjutnya produktivitas pada bulan Maret hingga bulan September 2020 produktivitas PT. Inka Bina Agro Wisesa tidak stabil terjadi naik dan turun produktivitas.

2. Analisis rasio

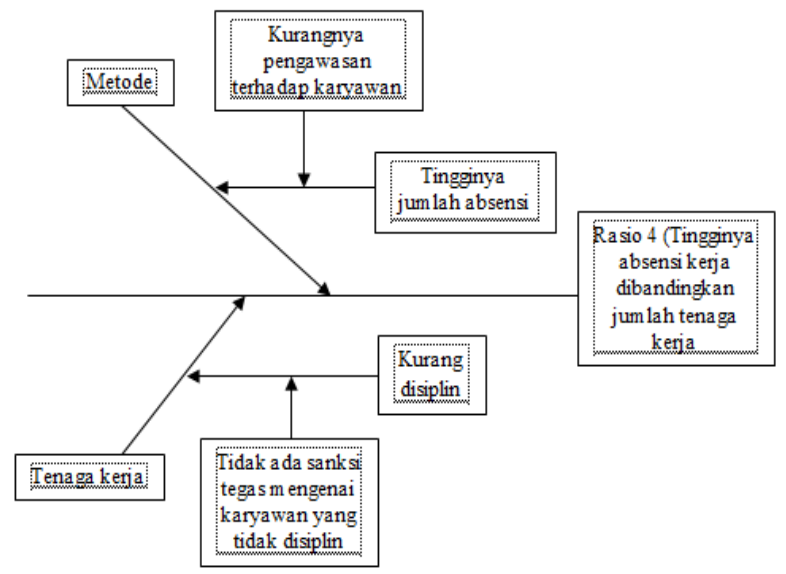

Gambar 3. Analisis Fishbone Rasio 3

Tabel 13. Strategi Peningkatan Produktivitas Tenaga Kerja

\begin{tabular}{|c|l|}
\hline Basic Event & Rekomendasi Perbaikan \\
\hline $\begin{array}{c}\text { Tingginya jumlah } \\
\text { absensi }\end{array}$ & $\begin{array}{l}\text { Melakukan pengawasan } \\
\text { kepada karyawan agar } \\
\text { tetap disiplin. }\end{array}$ \\
\hline $\begin{array}{c}\text { Sanksi yang kurang } \\
\text { tegas }\end{array}$ & $\begin{array}{l}\text { Memberikan sanksi kepada } \\
\text { karyawan yang tidak } \\
\text { disiplin }\end{array}$ \\
\hline
\end{tabular}

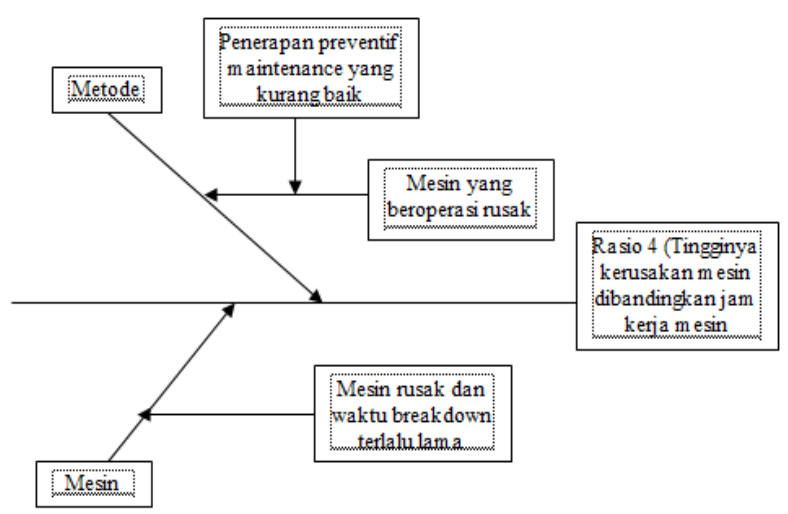

Gambar 4. Analisis Fishbone Rasio 4
Tabel 14. Strategi Peningkatan Produktivitas Mesin

\begin{tabular}{|c|c|}
\hline Basic Event & Rekomendasi Perbaikan \\
\hline $\begin{array}{c}\text { Kurangnya } \\
\text { pelatihan }\end{array}$ & $\begin{array}{c}\text { Adanya pelatihan terhadap } \\
\text { tenaga kerja mengenai } \\
\text { perawatan mesin. }\end{array}$ \\
\hline $\begin{array}{c}\text { Penerapan } \\
\text { preventif } \\
\text { maintenance yang } \\
\text { kurang baik }\end{array}$ & $\begin{array}{c}\text { Melakukan pengecekan } \\
\text { dan perawatan mesin } \\
\text { secara berkala }\end{array}$ \\
\hline
\end{tabular}

\section{Evaluasi Tingkat Produktivitas}

Evaluasi tingkat produktivitas perusahaan yaitu menganalisis pola pertumbuhan produktivitas sehingga dapat diketahui perkembangan perusahaan selama periode pengukuran.

Berdasarkan hasil perhitungan maka diketahui bahwa pada rasio 3 (produktivitas tenaga kerja) dan rasio 4 (produktivitas mesin) memiliki tingkat persentase kinerja yang buruk sangat tinggi, yang artinya pada rasio 3 dan rasio 4 memiliki tingkat produktivitas yang buruk. Berbeda halnya dengan pencapaian produktivitas rasio 1 (produktivitas bahan baku) dan rasio 2 (produktivitas jam kerja) yang menunjukan rendahnya persentase kinerja yang buruk, yang artinya tingkat produktivitas rasio 1 dan rasio 2 memiliki tingkat produktivitas yang lebih baik dari pada rasio 3 dan rasio 4

\section{Kesimpulan}

Dari hasil pengolahan data yang telah dilakukan pada Bab sebelumnya pada penelitian ini, maka dapat penulis ambil beberapa kesimpulan sebagai berikut:

1. Hasil perhitungan indeks produktivitas setiap periode menggambarkan penurunan dan peningkatan produktivitas yang dicapai oleh perusahaan. Pada gambar 3.5 dapat dilihat bahwa setiap bulan mengalami perubahan produktivitas yang tidak stabil, pada bulan November 2019 Produktivitas PT. Inka Bina Agro Wisesa mengalami penurunan pada bulan November 2019 sebesar - 80,39\% dan mengalamai peningkatan yang cukup tinggi pada bulan berikutnya yaitu bulan Desember sebesar 594,96\%. Pada bulan berikutnya PT. Inka Bina Agro Wisesa. Pada bulan berikutnya PT. Inka Bina Agro Wisesa mengalami penurunan produktivitasnya pada bulan Januari 2020 dan pada bulan Februari 2020 sampai -23,73\%. Selanjutnya produktivitas pada bulan Maret hingga bulan September 2020 produktivitas PT. Inka Bina Agro Wisesa tidak stabil terjadi naik dan penurunan.

2. Langkah awal yang perlu dilakukan perusahaan untuk meningkatkan produktivitas adalah dengan memfokuskan perbaikan - perbaikan pada rasio-rasio yang memiliki kriteria buruk terbanyak, yaitu rasio 3 dan rasio 4. Meningkatkan nilai produktivitas tenaga kerja, yaitu melakukan pengawasan terhadap karyawan dan memberikan sanksi terhadap karyawan yang tidak disiplin. Meningkatkan nilai produktivitas 
mesin, yaitu dengan melakukan proses perawatan secara berkala untuk menghindari kerusakan yang sangat parah, Selain itu juga perlu untuk terus melakukan pelatihan pada karyawan terutama operator untuk menambahkan pengetahuan agar proses produksi berjalan dengan baik.

\section{Daftar Pustaka}

[1] Avianda, D., \& Yuniati, Y. Yuniar. 2014. Strategi Peningkatan Produktivitas di Lantai Produksi Menggunakan Metode Objective Matrix (OMAX). Jurnal Online Institut Teknologi Nasional, 1(04), 202213.

[2 ] Gaspersz, V. (2000). Manajemen Produktivitas Total. Jakarta: Gramedia Pustaka Utama.

[3 ] Rismayadi, Budi. "Faktor-Faktor Yang Mempengaruhi Produktivitas Karyawan (Studi Kasus Pada Cv Mitra Bersama Lestari Tahun 2014)." Jurnal Manajemen \& Bisnis Kreatif 1.1 (2015).

[4] Sinungan, Muchdarsyah. Produktivitas apa dan Bagaimana. Bumi Aksara, 2018.

[5 ] Syarifuddin, S., \& Yani, L. (2014). Analisis Produktivitas Perusahaan Pada UD. Karya Jaya. Industrial Engineering Journal, 3(2).

[6 ] Wahyuni, H. C., \& Setiawan, S. (2017). Implementasi Metode Objective Matrix (OMAX) Untuk Pengukuran Produktivitas Pada PT. ABC. PROZIMA (Productivity, Optimization and Manufacturing System Engineering), 1(1), 17-21.

[7 ] Zulhamsyah, D. (2014). Pengukuran Produktivitas di SOS Laboratory Balikpapan PT Trakindo Utama (Doctoral dissertation, President University). 